\title{
Stability analysis of oil yield in oil palm (Elaeis guineensis) progenies in different environments
}

\author{
M.Y. Rafii ${ }^{1,2}$, B.S. Jalani ${ }^{3}$, N. Rajanaidu ${ }^{4}$, A. Kushairi ${ }^{4}$, A. Puteh ${ }^{1}$ and \\ M.A. Latif ${ }^{1}$ \\ ${ }^{1}$ Department of Crop Science, Faculty of Agriculture, \\ Universiti Putra Malaysia, Serdang, Selangor, Malaysia \\ ${ }^{2}$ Institute of Tropical Agriculture, Universiti Putra Malaysia, \\ Serdang, Selangor, Malaysia \\ ${ }^{3}$ Faculty of Science and Technology, Universiti Sains Islam Malaysia, \\ Bandar Baru Nilai, Negeri Sembilan, Malaysia \\ ${ }^{4}$ Malaysian Palm Oil Board, Bandar Baru Bangi, Kajang, Selangor, Malaysia \\ Corresponding author: M.Y. Rafii \\ E-mail:mrafii@putra.upm.edu.my
}

Genet. Mol. Res. 11 (4): 3629-3641 (2012)

Received January 27, 2012

Accepted August 2, 2012

Published October 4, 2012

DOI http://dx.doi.org/10.4238/2012.October.4.10

ABSTRACT. We evaluated 38 dura $\mathrm{x}$ pisifera (DP) oil palm progenies in four locations in Malaysia for genotype by environment interaction and genotypic stability studies. The DP progenies derived from crosses between pisifera palms of AVROS, Serdang S27B, Serdang 29/36, and Lever Cameroon were chosen to be the males' parent and Deli dura palms designated as females' parent. All the locations differed in terms of soil physical and chemical properties, and the soil types ranged from coastal clay to inland soils. The genotype by environment interaction and stability of the individual genotypes were analyzed for oil yield trait using several stability techniques. A genotype by environment interaction was detected for oil yield and it had a larger variance component than genotypic variance $\left(\sigma_{\mathrm{gl}}^{2} / \sigma_{\mathrm{g}}^{2}=139.7 \%\right)$. Genotype by environment 
interaction of oil yield was largely explained by a non-linear relationship between genotypic and environmental values. Overall assessment of individual genotypic stability showed that seven genotypes were highly stable and had consistent performance over the environments for the oil yield trait [total individual genotype stability scored more than 10 and mean oil yielded above the average of the environment (genotype means are more than $34.37 \mathrm{~kg} \cdot$ palm $^{-1}$.year ${ }^{-1}$ )]. These genotypes will be useful for oil palm breeding and tissue culture programs for developing high oil yielding planting materials with stable performance.

Key words: Oil palm; Elaeis guineensis; Stability statistics; Genotype by environment interaction; Oil yield stability

\section{INTRODUCTION}

The oil palm is native to West Africa where it still exists fairly extensively as wild and semi-wild groves along the western coast in a narrow belt from Senegal to Angola and towards the central regions in Congo, Uganda and Tanzania (Hartley, 1988). The oil palm was first introduced to the Far East in Bogor, Java in 1848. Four palms were introduced from West Africa and established at the Bogor Botanical Garden. Materials derived from this introduction were used to establish the first plantations in Indonesia and Malaysia. Elaeis guineensis Jacq. (2n $=2 \mathrm{x}=32$ ) is a member of the family Palmae in the same botanical tribe, Cocoineae as the coconut, Cocos nucifera (Hartley, 1988). The oil palm is the most productive oil-bearing plant species. A hectare of oil palm in good growing conditions produces about 4.5 tons oil/year and 0.5 tons kernel oil/year (Robbelen, 1990). This is almost three times the yield of coconut and more than ten times that of soybean.

Malaysia is the major producer and exporter of palm oil in the world. Malaysia crude palm oil output in 2010 at 16.99 million tons was approximately $45 \%$ of the total world palm oil production (MPOB, 2011). The better price of palm oil and higher profitability of oil palm growing as compared to other plantation crops, such as rubber and cocoa, have resulted in an expansion in the hectarage of oil palm in this country. The area devoted to oil palm began to expand sharply from 60,000 ha in 1964 to 4.85 million ha in 2010 (MPOB, 2011). In maintaining the competitive edge of Malaysian palm oil in the world market, it is important that the yield/hectare increases continuously. Yield improvement depends on agronomic practices and management, pest and disease control, and the genetically superior and stable performance of planting material. Oil palm is a perennial crop, and thus, it is important that high-quality planting materials be produced, as the economic life of oil palm trees is more than 25 years.

Multi-location trials play an important role in breeding program in evaluating the adaptability of new varieties in various environments. The most obvious effects of the presence of genotype by environment $(\mathrm{GxE})$ interaction are to reduce the correlation between the phenotype and the genotype (Comstock and Moll, 1963). The GxE interaction implies an inconsistent performance of a genotype relative to the others tested over a range of environments. The inconsistencies can be the result of a difference in the ranking of genotypes from one environment to another (cross-over interaction), or the changes in the absolute differences between genotypes, while leaving the rank order unchanged (non-crossover interaction; Hill, 
1975; Caligari, 1993). According to Knight (1970), the major objective of plant breeding is to select genotypes that are consistently high yielding over a range of environments, regardless of location and/or season. Thus, GxE interactions cause selection to be inefficient because the selected genotypes may fail to repeat their relative performance in different environments.

One of the earlier references to GxE interaction was by Fisher and Mackenzie (1923), even before the development of the stability tool, analysis of variance (ANOVA; Freeman, 1973). Various models have been proposed to describe GxE interactions. Many of these are just extensions to the basic model described by Allard (1999), through adding on components such as locations and seasons or years. Statistical analysis of the GxE interaction term was attempted in 1926 by Fisher, while Immer et al. (1933) showed that the analysis of GxE interaction may be carried out using ANOVA statistical procedure. Varietal yield trials are considered as factorial designs, separating out the effects due to the factors genotypes, environments and GxE interactions. In other words, GxE effects may be studied through the use of analysis of variance components.

Various stability statistics have been developed to measure the stability of performance of individual genotypes. Plaiested (1960) and Shukla (1972) developed methods of partitioning the variance components of the GxE interaction among genotypes. The stability variance statistics $\left(\sigma^{2}\right)$ developed by Shukla (1972) measures the contribution of each genotype to GxE interaction. A genotype is considered stable if its GxE variance is small. So far, none of the oil palm studies on GxE interaction has reported this statistics.

The use of the regression method to investigate GxE interaction was originally described by Yates and Cochran (1938), but the method was essentially neglected until Finlay and Wilkinson (1963) applied it to the analysis of barley adaptability. The regression method has been improved by various workers (Eberhart and Russell, 1966; Perkins and Jinks, 1968). In the joint regression analysis, the value of $\beta$ (Finlay and Wilkinson, 1963) or $b_{i}-1$ (Perkins and Jinks, 1968), is used as measure of stability. A genotype showing no GxE interaction, i.e., one that is stable, would have a $\beta_{\mathrm{i}}$ of zero, and the genotype sensitive to environment would have a value greater than zero.

Eberhart and Russell (1966) regressed mean yield of individual genotypes on environmental indices, which were calculated by subtracting the grand mean from the mean yield of all genotypes in each environment. In Eberhart and Russell's model, in addition to the regression coefficient mentioned above, they considered mean square deviation from regression $\left(S^{2} d\right)$. The deviation from regression is a measure of departure of individual genotype from its linear response to the environment. A highly stable genotype is one with $b=1.0$ and $\mathrm{S}^{2} \mathrm{~d}=0$. Several studies on individual genotype stability in oil palm and other crops have used this method (Hutomo and Pamin, 1992; Rajanaidu et al., 1992; Badiger et al., 2009; Tiawari et al., 2011).

Francis and Kannenberg (1978) considered a genotype with a low coefficient of variation $(\mathrm{CV})$ but high mean yield to be stable. Genotypes with a very high $\mathrm{CV}$ and low mean yield would be considered unstable and undesirable. Lee and Donough (1993) and Rajanaidu et al. (1993) used this method to determine stable genotypes in oil palm populations. Meanwhile, Yong et al. (1993) used a method of mean against standard deviation (SD) to study the stability of genotypes in an oil palm population. The stable genotypes are defined in the same manner as in Francis and Kannenberg's method.

Lin and Binns (1988) proposed a method called superiority measure (P). $\mathrm{P}$ is defined as the distance mean square between the genotype's response and the maximum response averaged over all locations. None of the oil palm studies on GxE interaction have reported this statistic. Huhn (1979) proposed a non-parametric statistic $\left(\mathrm{S}^{3}\right)$ that was based on ranks of 
genotypes in each environment. The non-parametric statistic has been used in maize (Kang and Pham, 1991) and lentil (Sabaghnia et al., 2006).

Kang (1988) developed a simple stability statistic called the rank sum method (RS) for selecting high yielding and stable genotypes. The rank sum values are based on mean character rank and Shukla's stability variance rank. The lowest RS values indicate stable and high yielding genotypes. The RS method has been improved by Kang et al. (1990) to the modified rank sum (MRS), which takes into account the significant levels of stability variance. This method was found to be more yield oriented than the RS method (Kang, 1993). In the present study, 38 oil palm progeny derived from crosses between dura and pisifera (DP) were tested at four different locations for oil yield trait. The objective of this study was to estimate and quantify the level of GxE interaction for this trait and to identify and select high oil yielding and stable oil palm genotypes using several techniques of stability analysis.

\section{MATERIAL AND METHODS}

Thirty-eight DP oil palm progeny derived from crosses between Deli dura (D) females' parent and AVROS, Serdang S27B, Serdang 29/36, and Lever Cameroon pisifera (P) males were tested in each of four different locations in Malaysia, viz. Teluk Intan in Perak State, Carey Island in Selangor State, Kepong in Selangor State, and Kluang in Johor State. The progeny were planted in a completely block design in two replications at each location and five palms were planted for each progeny and replication. The planting distance was $8.8 \times 8.8 \times 8.8 \mathrm{~m}$ in equilateral triangular arrangement with planting density of $148 \mathrm{palms} / \mathrm{ha}$ (Noh et al., 2010). Total experimental area at each location was about 2.7 ha. Data collection of fresh fruit bunch yield commenced from 37 months after planting. Harvesting was carried out at 10-day intervals or three times a month for a period of four years consecutively at each location. The fresh fruit bunch yield data were then summarized annually. The bunch analysis method of Rao et al. (1983) applied by Junaidah et al. (2011) was used to estimate the bunch quality and oil to bunch ratio characters. The oil yield data of individual palms derived from multiplication of their fresh fruit bunch yield by their oil to bunch ratio. Standard oil palm plantation management practices for fertilization and pest and weed control were followed at each location.

Analysis of variance in this study was computed using individual palm data. Stability analyses for the 38 progenies were conducted using several techniques namely genotype means against their coefficient of variation (Francis and Kannenberg, 1978), genotype means against their standard deviation (Yong et al., 1993), stability variances following removal of heterogeneity due to the linear effect of a covariate (Shukla, 1972), ecovalence mean square (Kang and Miller, 1984), joint regression analysis (Eberhart and Russell, 1966), Huhn's nonparametric stability statistic (Huhn, 1979), Lin and Binns' superiority measure (Lin and Binns, 1988), and Kang's rank sum statistics (Kang, 1988; Kang et al., 1991).

\section{RESULTS}

\section{Genotype x environment interaction}

The environment at Teluk Intan was the best for oil yield production in comparison with the other three locations (Table 1). The progeny means over locations showed that DP23 
has the highest oil yield $\left(41.59 \mathrm{~kg} \cdot\right.$ palm $^{-1} \cdot$ year $\left.^{-1}\right)$, whereas progeny DP32 has the lowest $(29.26$ $\left.\mathrm{kg} \cdot \mathrm{palm}^{-1} \cdot \mathrm{year}^{-1}\right)$. ANOVA revealed that the differences in progeny and location items were highly significant (Table 2).

Table 1. Progeny means for oil yield $\left(\mathrm{kg} \cdot \mathrm{palm}^{-1} \cdot \mathrm{year}^{-1}\right)$ in individual locations.

\begin{tabular}{|c|c|c|c|c|c|c|}
\hline \multirow[t]{2}{*}{ No. } & \multirow[t]{2}{*}{ Progeny code } & \multicolumn{4}{|c|}{ Locations } & \multirow[t]{2}{*}{ Progeny mean } \\
\hline & & Teluk Intan & Carey Island & Kepong & Kluang & \\
\hline 1 & DP1 & 44.51 & 32.29 & 30.49 & 18.15 & 31.36 \\
\hline 2 & DP2 & 53.93 & 43.37 & 31.17 & 21.37 & 37.46 \\
\hline 3 & DP3 & 46.19 & 47.72 & 33.71 & 29.35 & 39.24 \\
\hline 4 & DP4 & 41.82 & 39.44 & 27.99 & 18.67 & 31.98 \\
\hline 5 & DP5 & 42.06 & 30.45 & 31.01 & 16.75 & 30.07 \\
\hline 6 & DP6 & 41.44 & 42.14 & 27.57 & 28.85 & 35.00 \\
\hline 7 & DP7 & 46.90 & 54.47 & 28.32 & 29.88 & 39.89 \\
\hline 8 & DP8 & 55.82 & 45.47 & 29.54 & 19.45 & 37.62 \\
\hline 9 & DP9 & 40.32 & 40.26 & 32.18 & 22.40 & 33.79 \\
\hline 10 & DP10 & 42.08 & 44.54 & 36.57 & 26.47 & 37.41 \\
\hline 11 & DP11 & 41.40 & 31.71 & 31.73 & 22.77 & 31.90 \\
\hline 12 & DP12 & 37.51 & 47.68 & 28.37 & 20.56 & 33.53 \\
\hline 13 & DP13 & 37.87 & 37.10 & 27.72 & 22.21 & 31.22 \\
\hline 14 & DP14 & 43.48 & 35.70 & 34.41 & 18.00 & 32.90 \\
\hline 15 & DP15 & 44.31 & 42.43 & 32.72 & 14.79 & 33.56 \\
\hline 16 & DP16 & 38.74 & 46.05 & 37.00 & 22.50 & 36.07 \\
\hline 17 & DP17 & 44.74 & 35.77 & 29.96 & 25.91 & 34.10 \\
\hline 18 & DP18 & 47.39 & 39.68 & 32.81 & 18.69 & 34.64 \\
\hline 19 & DP19 & 42.94 & 50.63 & 29.78 & 29.89 & 38.31 \\
\hline 20 & DP20 & 37.32 & 45.56 & 42.00 & 25.58 & 37.62 \\
\hline 21 & DP22 & 34.49 & 40.90 & 32.70 & 31.51 & 34.94 \\
\hline 22 & DP23 & 50.56 & 52.39 & 33.74 & 29.69 & 41.59 \\
\hline 23 & DP24 & 55.04 & 43.43 & 34.64 & 22.73 & 38.96 \\
\hline 24 & DP25 & 53.51 & 43.21 & 30.69 & 28.06 & 38.87 \\
\hline 25 & DP26 & 48.79 & 55.09 & 30.99 & 16.06 & 37.73 \\
\hline 26 & DP27 & 48.13 & 43.02 & 27.69 & 23.95 & 35.70 \\
\hline 27 & DP28 & 44.10 & 42.29 & 32.31 & 16.44 & 33.79 \\
\hline 28 & DP29 & 41.26 & 36.43 & 30.40 & 23.26 & 32.84 \\
\hline 29 & DP30 & 36.81 & 43.51 & 28.93 & 18.48 & 31.93 \\
\hline 30 & DP31 & 38.50 & 33.21 & 28.94 & 20.42 & 30.27 \\
\hline 31 & DP32 & 30.56 & 36.90 & 32.76 & 16.81 & 29.26 \\
\hline 32 & DP34 & 35.87 & 34.26 & 31.85 & 27.19 & 32.29 \\
\hline 33 & DP35 & 43.67 & 32.41 & 35.71 & 20.06 & 32.96 \\
\hline 34 & DP36 & 34.71 & 38.39 & 33.42 & 13.67 & 30.04 \\
\hline 35 & DP37 & 38.87 & 32.91 & 31.21 & 14.52 & 29.38 \\
\hline 36 & DP38 & 37.19 & 35.36 & 30.95 & 19.51 & 30.75 \\
\hline 37 & DP39 & 42.57 & 40.98 & 50.57 & 24.30 & 34.60 \\
\hline 38 & DP40 & 35.83 & 46.79 & 28.06 & 18.64 & 32.33 \\
\hline Loc: & & 42.66 & 41.16 & 31.64 & 22.00 & 34.37 \\
\hline Min & & 30.56 & 30.45 & 27.57 & 13.67 & 29.26 \\
\hline Max & & 55.82 & 55.09 & 50.57 & 31.51 & 41.59 \\
\hline LSD & & 10.26 & 13.37 & 8.39 & 12.54 & 10.68 \\
\hline
\end{tabular}

The mean square of the item of our primary interest, progeny $\mathrm{x}$ location interaction, was highly significant for yield trait. The magnitude of GxE variance for oil yield was 7.13\% and had a larger variance of the progeny $\mathrm{x}$ location item as compared to the genotypic variance (Table 2). The results of ANOVA for regression analysis showed that genotypes, environments (E) $+\mathrm{GxE}$ ), E (linear) and pooled deviations showed highly significant differences and that GxE (linear) was not significantly different (Table 3 ). These results indicated that, a significant part of GxE interaction was largely explained by a non-linear relationship between genotypic and environmental values. 
Table 2. Mean squares and variance components of full-sib analysis over locations for oil yield.

\begin{tabular}{|c|c|c|}
\hline Source & d.f. & Mean square \\
\hline Progenies (G) & 37 & $333.06 * *$ \\
\hline Locations (L) & 3 & $27405.86 * *$ \\
\hline Replications in location $(\mathrm{R} / \mathrm{L})$ & 4 & 825.21 \\
\hline Gx L & 111 & $175.57 * *$ \\
\hline $\mathrm{G} \times \mathrm{R} / \mathrm{L}$ & 148 & $120.52 * *$ \\
\hline Error & 1005 & 112.53 \\
\hline$\overline{\sigma_{g}^{2}}$ & $\begin{array}{c}5.01 \\
(2.28)\end{array}$ & $\begin{array}{c}1.08 \\
(6.82)\end{array}$ \\
\hline$\sigma_{1}^{2}$ & $\begin{array}{c}88.81 \\
(40.35)\end{array}$ & $\begin{array}{c}4.86 \\
(30.68)\end{array}$ \\
\hline$\sigma_{\mathrm{r} 1}^{2}$ & $\begin{array}{c}4.72 \\
(2.14)\end{array}$ & $\begin{array}{c}0.03 \\
(0.19)\end{array}$ \\
\hline$\sigma_{\mathrm{gl}}^{2}$ & $\begin{array}{c}7.00 \\
(3.18)\end{array}$ & $\begin{array}{c}0.34 \\
(2.15)\end{array}$ \\
\hline$\sigma_{g(f / l)}^{2}$ & $\begin{array}{c}2.03 \\
(0.92)\end{array}$ & $\begin{array}{c}0.32 \\
(2.15)\end{array}$ \\
\hline$\sigma_{w}^{2}$ & $\begin{array}{l}112.53 \\
(51.13)\end{array}$ & $\begin{array}{c}9.21 \\
(58.41)\end{array}$ \\
\hline G x E (\%) & 7.13 & 6.03 \\
\hline$\sigma_{\mathrm{gl}}^{2} / \sigma_{\mathrm{g}}^{2}(\%)$ & 139.72 & 31.48 \\
\hline
\end{tabular}

**Significant at $\mathrm{P} \leq 0.01$. Variance component as percentage of total variance in shown in parentheses. d.f. $=$ degrees of freedom.

Table 3. Analysis of variance for regression of oil yield.

\begin{tabular}{lcc}
\hline Source & d.f. & Mean square \\
\hline Genotypes (G) & 37 & $333.06^{* *}$ \\
Environments (E) $+(\mathrm{GxE})$ & 114 & $892.15^{* *}$ \\
E (linear) & $(1)$ & $82217.56^{* *}$ \\
GxE (linear) & $(37)$ & 194.32 \\
Pooled deviations & $(76)$ & $161.81^{* *}$ \\
Replications in E (R/E) & 4 & $825.21^{* *}$ \\
Gx R/E & 148 & $120.52^{* *}$ \\
Pooled error & 1005 & 112.53 \\
\hline
\end{tabular}

**Significant at $\mathrm{P} \leq 0.01$. d.f. $=$ degrees of freedom.

\section{Genotype stability analysis}

In the present study, several techniques were used to determine the stability of individual genotypes. Genotype with a high CV or SD and mean would be considered below the average stability, while those with a low CV or SD and mean would be among the above average stability group. Genotypes with a high CV or SD and low mean would be clearly unstable and undesirable. Considering the above definition, nine genotypes (DP3, DP6, DP10, DP20, DP22, DP23, DP25, DP27, and DP39) were highly stable over environments by following genotype means against their CV (Figure 1), whereas five of the above genotypes (DP6, DP10, DP22, DP25, and DP39) remained highly stable using genotype means against their SD (Figure 2). On the other hand, of 38 genotypes, 12 genotypes were identified to be highly unstable by following genotype means against their CV. However, some genotypes (six) were highly unstable using genotype means versus their SD (Figures 1 and 2). 


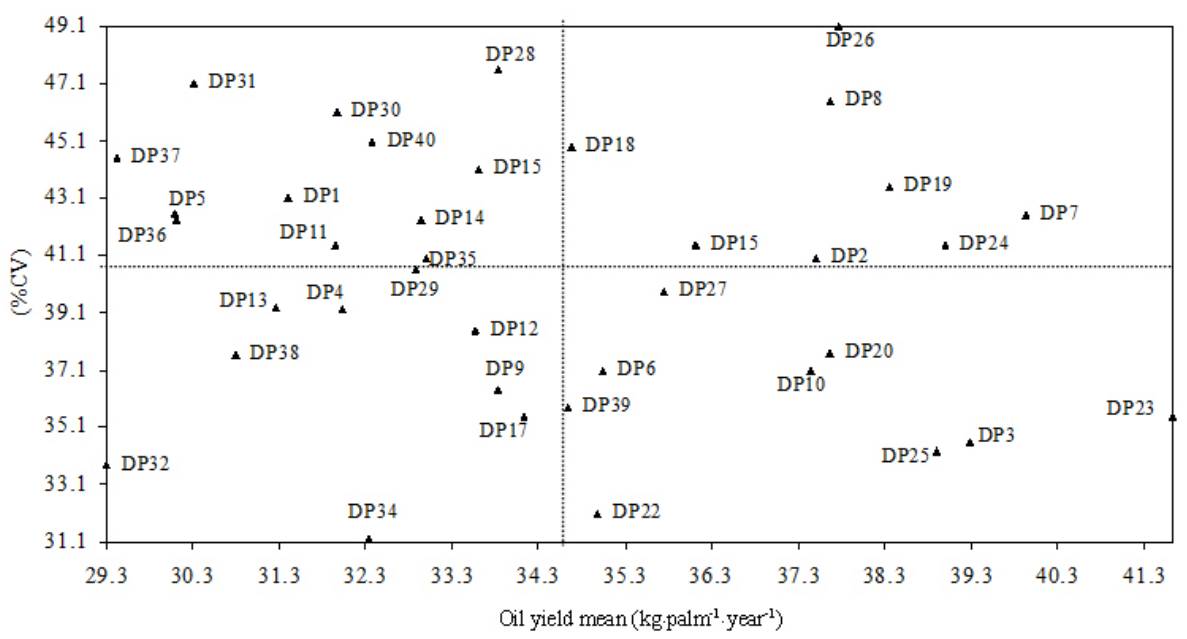

Figure 1. Plots of mean genotypes against their respective coefficient of variation (CV) of individual genotypes for oil yield.

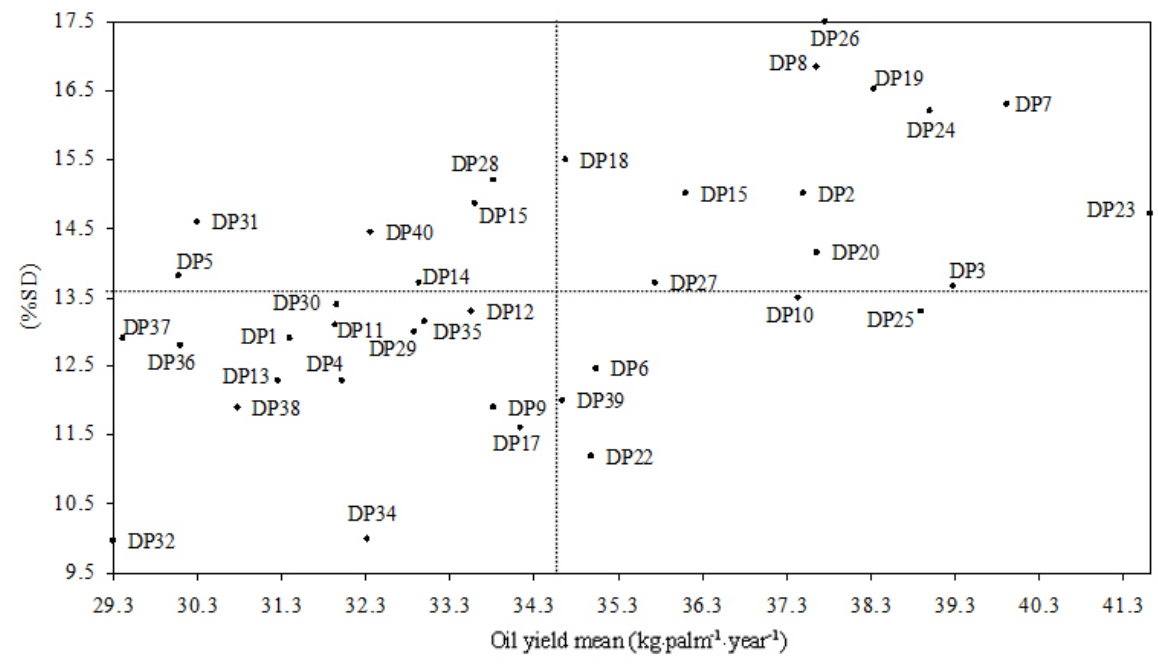

Figure 2. Plots of mean genotypes against their respective standard deviation (SD) of individual genotypes for oil yield.

GxE interaction was partitioned into stability variance $\left(\sigma^{2}\right)$ and stability variance after the influence of environmental index (covariate) was removed $\left(\mathrm{s}^{2}\right)$ and was calculated for individual genotypes according to Shukla (1972). Highly significant $\sigma^{2}$ values (implying highly unstable) were found in oil yield trait for DP8, DP24 and DP28 and significant $\sigma^{2}$ values (implying unstable) were obtained for DP28, DP24 and DP28 (Table 4). According to the s² statistic, DP3 was a highly unstable genotype, and the six genotypes DP13, DP19, DP22, DP27, DP37, and DP40 were judged to be unstable. Genotypes DP8 and DP28 had highly significant WMS values, indicating that the performance of these genotypes was highly inconsistent with environmental changes. The unstable genotypes were DP3, DP22 and DP24. 
Table 4. Mean and mean rank, and stability statistics for oil yield.

\begin{tabular}{|c|c|c|c|c|c|c|c|c|c|c|c|c|c|c|}
\hline No. & $\begin{array}{c}\text { Progeny } \\
\text { code }\end{array}$ & $\begin{array}{c}\text { Mean } \\
\left(\mathrm{kg} \cdot \text { palm }^{\cdot-1} \text { year }^{-1}\right)\end{array}$ & $\begin{array}{c}\text { Mean } \\
\text { rank }\end{array}$ & $\sigma^{2}$ & $\sigma^{2}$ rank & $s^{2}$ & WMS & $\mathrm{b}$ & $\mathrm{S}^{2} \mathrm{~d}$ & $r^{2}$ & $\mathrm{~S}^{3}$ & $\mathrm{P}$ & RS & MRS \\
\hline 1 & DP1 & 31.36 & 31.0 & 166.2 & 20.0 & 252.4 & 167.1 & 1.0 & 187.7 & 0.82 & 23.6 & 153.7 & 51.0 & 31.0 \\
\hline 2 & DP2 & 37.46 & 10.0 & 186.3 & 24.0 & 280.3 & 186.0 & 1.4 & 116.1 & 0.93 & $7.8^{+}$ & $77.5^{+}$ & $34.0^{+}$ & $10.0^{++}$ \\
\hline 3 & DP3 & 39.24 & 3.0 & $315.9 *$ & 34.0 & $435.3 * *$ & $312.1^{*}$ & 0.9 & 9.8 & 0.93 & $0.7^{++}$ & $54.5^{++}$ & $37.0^{+}$ & $13.0^{+}$ \\
\hline 4 & DP4 & 31.98 & 28.0 & 172.84 & 21.0 & 172.6 & 172.9 & 1.1 & 0.0 & 1.00 & $8.9^{+}$ & 139.5 & 49.0 & 28.0 \\
\hline 5 & DP5 & 30.07 & 35.0 & 255.5 & 32.0 & 177.3 & 253.4 & 1.0 & 213.8 & 0.79 & 21.6 & 174.6 & 67.0 & 35.0 \\
\hline 6 & DP6 & 35.00 & 14.0 & 46.6 & 7.0 & 64.9 & 50.1 & 0.7 & 111.6 & 0.77 & 29.2 & $113.8^{+}$ & $21.0^{++}$ & $14.0^{+}$ \\
\hline 7 & DP7 & 39.89 & 2.0 & 9.8 & 1.0 & 1.5 & 14.3 & 1.2 & $360.6^{*}$ & 0.79 & 23.2 & $72.2^{++}$ & $3.0^{++}$ & $2.0^{++}$ \\
\hline 8 & DP8 & 37.62 & 8.5 & $435.7 * *$ & 37.0 & 203.4 & $428.6^{* *}$ & 1.1 & 140.9 & 0.94 & 22.5 & $85.0^{+}$ & 45.5 & 28.5 \\
\hline 9 & DP9 & 33.79 & 19.5 & 10.1 & 2.0 & 2.6 & 14.6 & 0.9 & 0.0 & 0.99 & $2.6^{++}$ & $110.2^{+}$ & $21.5^{++}$ & $19.5^{+}$ \\
\hline 10 & DP10 & 37.41 & 11.0 & 47.3 & 8.0 & 35.2 & 50.8 & 0.8 & 0.0 & 0.95 & $4.1^{++}$ & $65.2^{++}$ & $19.0^{++}$ & $11.0^{+}$ \\
\hline 11 & DP11 & 31.90 & 30.0 & 180.9 & 22.0 & 166.8 & 180.8 & 0.9 & 106.2 & 0.76 & 18.1 & 148.2 & 52.0 & 30.0 \\
\hline 12 & DP12 & 33.53 & 22.0 & 121.1 & 15.0 & 182.4 & 122.6 & 1.1 & 243.2 & 0.81 & 25.1 & 125.4 & $37.0^{+}$ & 22.0 \\
\hline 13 & DP13 & 31.22 & 32.0 & 213.9 & 26.0 & $311.5^{*}$ & 212.9 & 0.8 & 0.0 & 0.98 & $13.0^{+}$ & 156.8 & 58.0 & 32.0 \\
\hline 14 & DP14 & 32.90 & 24.0 & 152.0 & 19.0 & 224.6 & 152.6 & 1.0 & 120.9 & 0.87 & 22.3 & 121.5 & 43.0 & 24.0 \\
\hline 15 & DP15 & 33.56 & 21.0 & 147.2 & 18.0 & 45.9 & 148.0 & 1.4 & 0.0 & 0.98 & 18.8 & $111.4^{+}$ & $39.0^{+}$ & $21.0^{+}$ \\
\hline 16 & DP16 & 36.07 & 12.0 & 136.4 & 17.0 & 147.5 & 137.5 & 0.9 & 160.8 & 0.81 & $13.3^{+}$ & $79.9^{+}$ & $29.0^{+}$ & $12.0^{+}$ \\
\hline 17 & DP17 & 34.10 & 18.0 & 37.6 & 4.0 & 6.4 & 41.4 & 0.8 & 87.8 & 0.82 & $15.6^{+}$ & 119.0 & $22.0^{++}$ & $18.0^{+}$ \\
\hline 18 & DP18 & 34.64 & 16.0 & 96.3 & 12.0 & 79.5 & 98.4 & 1.2 & 23.5 & 0.95 & $10.6^{+}$ & $98.5^{+}$ & $28.0^{+}$ & $16.0^{+}$ \\
\hline 19 & DP19 & 38.31 & 6.0 & 252.7 & 31.0 & $372.1^{*}$ & 250.9 & 0.9 & $300.0^{*}$ & 0.71 & 16.9 & $77.6^{+}$ & $37.0^{+}$ & $6.0^{++}$ \\
\hline 20 & DP20 & 37.62 & 8.5 & 121.3 & 16.0 & 154.4 & 122.8 & 0.7 & $330.8 *$ & 0.57 & 18.1 & $67.7^{++}$ & $24.5^{+}$ & $8.5^{++}$ \\
\hline 21 & DP22 & 34.94 & 15.0 & $343.4 *$ & 35.0 & $403.9^{*}$ & $338.4^{*}$ & 0.3 & 46.3 & 0.50 & 32.5 & 122.0 & 50.0 & 25.0 \\
\hline 22 & DP23 & 41.59 & 1.0 & 87.6 & 10.0 & 21.1 & 90.0 & 1.2 & 88.5 & 0.91 & $0.4^{++}$ & $40.2^{++}$ & $11.0^{++}$ & $1.0^{++}$ \\
\hline 23 & DP24 & 38.96 & 4.0 & $430.0 * *$ & 36.0 & 103.7 & $423.2^{*}$ & 1.4 & 126.2 & 0.92 & $4.1^{++}$ & $58.4^{++}$ & 40.0 & 24.0 \\
\hline 24 & DP25 & 38.87 & 5.0 & 114.0 & 14.0 & 148.2 & 115.6 & 1.1 & 237.3 & 0.82 & $9.1^{+}$ & $69.2^{++}$ & $19.0^{++}$ & $5.0^{++}$ \\
\hline 25 & DP26 & 37.73 & 7.0 & 226.0 & 27.0 & 187.9 & 224.6 & 1.8 & 120.9 & 0.95 & 31.4 & $83.9^{+}$ & $34.0^{+}$ & $7.0^{++}$ \\
\hline 26 & DP27 & 35.70 & 13.0 & 211.8 & 25.0 & $305.3^{*}$ & 210.8 & 1.2 & 94.9 & 0.91 & 24.6 & $98.2^{+}$ & $38.0^{+}$ & $13.0^{+}$ \\
\hline 27 & DP28 & 33.79 & 19.5 & $609.5^{* *}$ & 38.0 & 182.5 & $597.7 * *$ & 1.3 & 0.0 & 0.99 & $13.9^{+}$ & $107.7^{+}$ & 57.5 & 39.5 \\
\hline 28 & DP29 & 32.84 & 25.0 & 59.0 & 9.0 & 34.1 & 62.2 & 0.8 & 0.0 & 0.96 & $7.3^{+}$ & 123.4 & $34.0^{+}$ & 25.0 \\
\hline 29 & DP30 & 31.93 & 29.0 & 45.1 & 6.0 & 23.4 & 48.7 & 1.1 & 80.1 & 0.90 & 21.7 & 141.7 & $35.0^{+}$ & 29.0 \\
\hline 30 & DP31 & 30.27 & 34.0 & 94.4 & 11.0 & 139.2 & 96.6 & 0.8 & 0.0 & 0.95 & $6.0^{++}$ & 171.2 & 45.0 & 34.0 \\
\hline 31 & DP32 & 29.26 & 38.0 & 45.1 & 5.0 & 29.4 & 48.6 & 0.8 & 225.2 & 0.68 & 31.6 & 187.8 & 43.0 & 34.0 \\
\hline 32 & DP34 & 32.29 & 27.0 & 12.3 & 3.0 & 9.8 & 16.7 & 0.4 & 0.0 & 0.98 & 28.8 & 150.1 & $30.0^{+}$ & 27.0 \\
\hline 33 & DP35 & 32.96 & 23.0 & 281.3 & 33.0 & -0.3 & 278.5 & 0.9 & 276.7 & 0.71 & 24.8 & 126.7 & 56.0 & 23.0 \\
\hline 34 & DP36 & 30.04 & 36.0 & 240.0 & 29.0 & 292.5 & 238.2 & 1.1 & 212.3 & 0.82 & 42.1 & 167.1 & 65.0 & 36.0 \\
\hline 35 & DP37 & 29.38 & 37.0 & 244.1 & 30.0 & $347.0^{*}$ & 242.3 & 1.0 & 96.7 & 0.88 & 19.8 & 180.3 & 67.0 & 37.0 \\
\hline 36 & DP38 & 30.75 & 33.0 & 186.0 & 23.0 & 279.0 & 185.7 & 0.8 & 0.0 & 0.96 & $5.7^{++}$ & 158.2 & 56.0 & 33.0 \\
\hline 37 & DP39 & 34.60 & 17.0 & 103.3 & 13.0 & 157.0 & 105.2 & 0.9 & 0.0 & 0.98 & 8.3 & $53.3^{++}$ & $30.0^{+}$ & $17.0^{+}$ \\
\hline 38 & DP40 & 32.33 & 26.0 & 233.0 & 28.0 & $335.8^{*}$ & 231.4 & 1.1 & 265.7 & 0.81 & 39.2 & 142.6 & 54.0 & 26.0 \\
\hline
\end{tabular}

$*, * *$ Significant $\mathrm{P} \leq 0.05$ and $\mathrm{P} \leq 0.01$, respectively; ${ }^{+,++}$stable and highly stable, respectively. $\sigma^{2}=$ stability variance; $\mathrm{s}^{2}=$ stability variance (covariate); WMS = ecovalence mean square; $b=$ regression coefficient; $\mathrm{S}^{2} \mathrm{~d}=$ deviation mean square of regression, $\mathrm{r}^{2}=$ coefficient of determination, $\mathrm{S}^{3}=$ Huhn's non-parametric stability statistic; $\mathrm{P}=$ Lin and Binns' superiority measure statistic; RS = rank sum stability statistic; $M R S=$ modified rank sum stability statistic.

According to Eberhart and Russell (1966), a large variation in b values indicated large differences in genotypic responses to different environments. Only three genotypes (DP7, DP19 and DP20) had deviation mean square from regression $\left(\mathrm{S}^{2} \mathrm{~d}\right)$ that differed significantly from zero for oil yield. Based on Eberhart and Russell's graphical presentation, genotypes DP3, DP23 and DP25 were desirable because they had a high mean, where b was close to one and $\mathrm{S}^{2} \mathrm{~d}$ was not significantly different from zero (Figure 3). DP7 and DP19 had a high mean and $\mathrm{b}=1.0$; however, they were not regarded as stable for general adaptability because their $\mathrm{S}^{2} \mathrm{~d}_{\mathrm{i}}$ were significantly greater than zero, indicating that the linear response to environments was not consistent. 


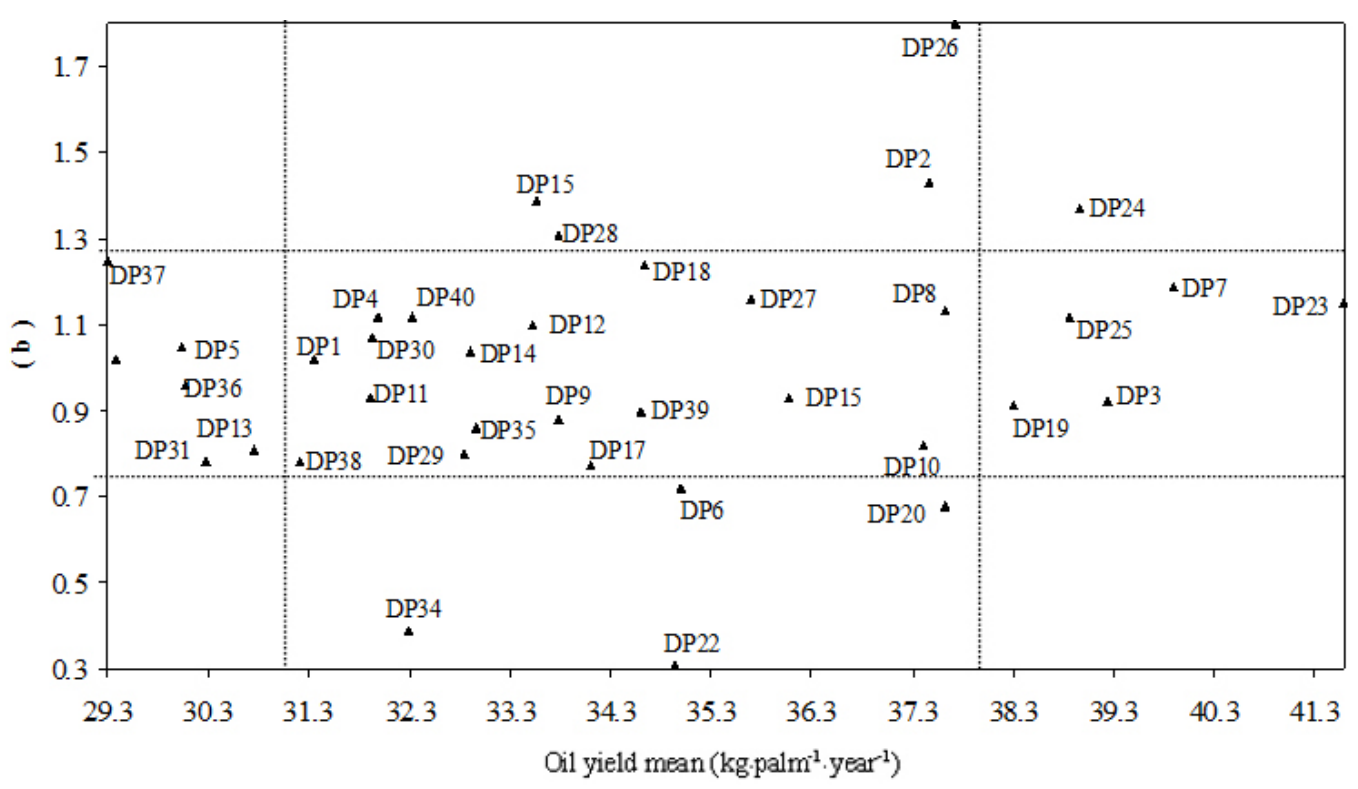

Figure 3. Plots of mean genotypes against their respective regression coefficients (b) for oil yield (vertical dotted lines: grand mean $\pm \mathrm{SD}$; horizontal dotted lines: $\mathrm{b}=1 \pm \mathrm{SD}$ ).

Huhn's non-parametric stability statistic $\left(\mathrm{S}^{3}\right)$ for individual genotypes is given in Table 4. Generally the smaller the $\mathrm{S}^{3}$ value is, the better the adaptability of a genotype is over a range of environments. In this study, a highly stable genotype had an $\mathrm{S}^{3}$ value equal to or less than $\mathrm{S}^{3}$ grand mean minus one $\mathrm{SD}$, and the stable one had an $\mathrm{S}^{3}$ value more than $\mathrm{S}^{3}$ grand mean minus SD but equal to or less than $\mathrm{S}^{3}$ grand mean. With that definition, DP3, DP9, DP10, DP23, DP24, DP31, and DP38 were classified as highly stable genotypes for oil yield, while the stable ones were DP2, DP4, DP13, DP16, DP17, DP18, DP19, DP25, DP28, DP29, DP31, and DP39. The stable genotypes according to Lin and Binns' superiority measure statistic (P) are defined in the same manner as in Huhn's non-parametric stability statistic $\left(\mathrm{S}^{3}\right)$. Highly stable genotypes for oil yield following the P statistic included D3, DP7, DP10, DP20, DP23, DP24, DP25, and DP39, whereas another 11 were considered to be stable.

Two stability statistics of Kang's rank sum methods were computed, namely, RS, and MRS stability statistics. According to Kang (1993), the RS stability statistic for each genotype was derived from the sum of character mean rank and Shukla's stability variance rank. In this method, equal weight of ranks was assigned to character mean and stability variance. Rank was assigned for oil yield mean with the genotype having the highest mean receiving the rank of one. In contrast, for stability variance rank was assigned with the lowest $\sigma^{2}$ value receiving the rank of one.

The MRS stability statistic of individual genotypes was derived from the sum of character mean rank and stability variance ranking, where the rank of stability variances were assigned in a different manner as compared to RS statistic. For this method, rating of zero, 10 and 20 were given for non-significant $\sigma^{2}$, significant at $5 \%$ probability level, significant at $1 \%$ probability level, respectively as suggested by Kang (1988) and Kang et al. (1990). For a 
general definition, the lowest RS or MRS values were considered to be the most desirable and stable genotypes over a range of environments.

In the present study, the definition of a highly stable genotype is one that has an RS or MRS value equal to or less than RS or MRS grand mean minus SD. While the stable genotype has an RS or MRS value of more than RS or MRS grand mean minus SD but equal to or less than or RS or MRS grand mean. On the other hand, the genotype with an RS or MRS value of more than its grand mean is considered unstable. Based on the above definitions, the highly stable genotypes included DP6, DP7, DP9, DP10, DP17, DP23, and DP25 by using the RS statistic, whereas genotypes DP2, DP7, DP19, DP20, DP23, DP25, and DP26 when applying the MRS statistic (Table 5). The total numbers of genotypes identified to be both highly stable and stable were 21 genotypes by following the RS statistic but only 17 genotypes when using the other method.

Table 5. Stability of individual genotypes as defined by various methods for oil yield.

\begin{tabular}{|c|c|c|c|c|c|c|c|c|c|c|c|c|c|}
\hline No. & $\begin{array}{l}\text { Progeny } \\
\text { code }\end{array}$ & Pisifera & $\begin{array}{c}\text { Mean rank } \\
\text { vs CV }\end{array}$ & Mean rank $v s \mathrm{SD}$ & $\sigma^{2}$ & $s^{2}$ & WMS & JR & $\mathrm{S}^{3}$ & $\mathrm{P}$ & $\mathrm{RS}$ & MRS & Total \\
\hline 1 & DP1 & 1 & - & + & + & + & + & + & - & - & - & - & 5 \\
\hline 2 & DP2 & 1 & - & - & + & + & + & - & + & + & + & ++ & 8 \\
\hline 3 & DP3 & 1 & ++ & - & - & - & - & ++ & ++ & ++ & + & + & 10 \\
\hline 4 & DP4 & 1 & + & + & + & + & + & + & + & - & - & - & 7 \\
\hline 5 & DP5 & 2 & - & + & + & + & + & - & - & - & - & - & 4 \\
\hline 6 & DP6 & 2 & ++ & ++ & + & + & + & - & - & + & ++ & + & 11 \\
\hline 7 & DP7 & 3 & - & - & + & + & + & - & - & ++ & ++ & ++ & 9 \\
\hline 8 & DP8 & 3 & - & - & - & + & - & + & - & + & - & - & 3 \\
\hline 9 & DP9 & 4 & + & + & + & + & + & + & ++ & + & ++ & + & 12 \\
\hline 10 & DP10 & 4 & ++ & ++ & + & + & + & + & ++ & ++ & ++ & + & 15 \\
\hline 11 & DP11 & 4 & - & + & + & + & + & + & - & - & - & - & 5 \\
\hline 12 & DP12 & 5 & + & + & + & + & + & + & - & - & + & - & 7 \\
\hline 13 & DP13 & 5 & + & + & + & - & + & + & + & - & - & - & 6 \\
\hline 14 & DP14 & 6 & - & - & + & + & + & + & - & - & - & - & 4 \\
\hline 15 & DP15 & 6 & - & - & + & + & + & - & - & + & + & + & 6 \\
\hline 16 & DP16 & 7 & - & - & + & + & + & + & + & + & + & + & 8 \\
\hline 17 & DP17 & 7 & + & + & + & + & + & + & + & & ++ & + & 10 \\
\hline 18 & DP18 & 8 & - & - & + & + & + & + & + & + & + & + & 8 \\
\hline 19 & DP19 & 8 & - & - & + & - & + & - & + & + & + & ++ & 7 \\
\hline 20 & DP20 & 9 & ++ & - & + & + & + & - & - & ++ & + & ++ & 10 \\
\hline 21 & DP22 & 9 & ++ & ++ & - & - & - & - & - & - & - & - & 4 \\
\hline 22 & DP23 & 10 & ++ & - & + & + & + & ++ & ++ & ++ & ++ & ++ & 15 \\
\hline 23 & DP24 & 10 & - & - & - & + & - & - & ++ & ++ & - & - & 5 \\
\hline 24 & DP25 & 10 & ++ & ++ & + & + & + & ++ & + & ++ & ++ & ++ & 16 \\
\hline 25 & DP26 & 11 & - & - & + & + & + & - & - & + & + & ++ & 7 \\
\hline 26 & DP27 & 11 & ++ & - & + & - & + & + & - & + & + & + & 8 \\
\hline 27 & DP28 & 12 & - & - & - & + & - & - & + & + & - & - & 3 \\
\hline 28 & DP29 & 12 & - & + & + & + & + & + & + & - & + & - & 7 \\
\hline 29 & DP30 & 13 & - & + & + & + & + & + & - & - & + & - & 6 \\
\hline 30 & DP31 & 13 & - & - & + & + & + & - & ++ & - & - & - & 5 \\
\hline 31 & DP32 & 13 & + & + & + & + & + & - & - & - & - & - & 5 \\
\hline 32 & DP34 & 14 & + & + & + & + & + & - & - & + & - & - & 6 \\
\hline 33 & DP35 & 14 & - & + & + & + & + & + & - & - & - & - & 5 \\
\hline 34 & DP36 & 14 & - & + & + & + & + & - & - & - & - & - & 4 \\
\hline 35 & DP37 & 15 & - & + & + & + & - & - & - & - & - & - & 3 \\
\hline 36 & DP38 & 15 & + & + & + & + & + & - & ++ & - & - & - & 7 \\
\hline 37 & DP39 & 15 & ++ & ++ & + & + & + & + & + & ++ & + & + & 13 \\
\hline 38 & DP40 & 15 & - & - & + & - & + & + & - & - & - & - & 3 \\
\hline
\end{tabular}

,,-+++ Unstable, stable and highly stable, respectively. $\mathrm{CV}=$ coefficient variation; $\mathrm{SD}=$ standard deviation; JR = joint regression analysis. For other abbreviations, see legend to Table 4. 


\section{DISCUSSION}

The environment at Teluk Intan was the best for oil yield in comparison with the other three locations. The results reported here were comparable to the studies by Lee and Donough (1993) and Tarmizi et al. (1992), where coastal soils (such as Teluk Intan and Carey Island) could support a good production compared to inland soil (such as Kluang). The mean square of the item of our primary interest, the progeny $\mathrm{x}$ location interaction, differed significantly for this trait. This confirmed the existence of GxE effects of oil yield trait in the DP population. On the other hand, Rajanaidu et al. (1993) reported a lack of GxE interaction for this trait in their studies on 32 DP genotypes tested at three locations.

In the present study, several techniques were used to determine the stability of individual genotypes. According to genotype-grouping techniques using genotypes mean against their CV (Francis and Kannenberg, 1978) and genotype means against their SD (Yong et al., 1993), a highly stable genotype has a low CV or SD but a high mean. Genotypes with a high CV or SD and mean would be considered below the average stability, while those with a low CV or SD and mean would be among the above average stability group. Genotypes with a high CV or SD and low mean would be clearly unstable and undesirable. From the above definition, nine genotypes (DP3, DP6, DP10, DP20, DP22, DP23, DP25, DP27, and DP39) were highly stable over environments by following genotype means against their CV, whereas five of the above genotypes (DP6, DP10, DP22, DP25, and DP39) remained highly stable using genotype means against their SD.

The ideal genotype as proposed by Eberhart and Russell (1966) would have a high mean performance over a range of environments, a regression coefficient of one and deviation mean square $\left(\mathrm{S}^{2} \mathrm{~d}\right)$ of zero. According to Breese (1969), genotypes with regression coefficients greater than 1.0 would be adapted to a more favorable environment, while those with coefficients less than one would be relatively better suited for less favorable growing conditions. A genotype with a smaller deviation mean square from regression was considered to be more stable. In the stability analysis, the regression of genotype mean on the environmental index resulted in regression coefficients ranging from 0.31 to 1.80 . Using Eberhart and Russell's graphical presentation, DP3, DP23 and DP25 were desirable genotypes because they had a high mean, b was close to 1 and $\mathrm{S}^{2} \mathrm{~d}$ did not significantly differ from zero. According to Huhn's non-parametric stability statistic $\left(\mathrm{S}^{3}\right)$ and Lin and Binns' superiority measure statistic (P), genotypes DP3, DP10, DP23, and DP24 were highly stable. Based on both RS and MRS stability statistics, DP7, DP23 and DP25 genotypes were highly stable.

\section{CONCLUSION}

In a plant breeding program, it is desirable to identify promising genotypes that may provide maximum yield over environments and show consistent performance. Seven genotypes (DP3, DP6, DP10, DP20, DP23, DP25, and DP39) were rated to be highly stable by the various stability parameters (score of 10 and mean above average oil yield over the environments). However, genotype DP24, which produced high oil yield (38.96 kg $\cdot$ palm $\left.^{-1} \cdot \mathrm{year}^{-1}\right)$, was identified to be stable by $\sigma_{\mathrm{i}}^{2}, \mathrm{~S}_{\mathrm{i}}^{3}$ and $\mathrm{P}_{\mathrm{i}}$ statistics only.

\section{REFERENCES}

Allard RW (1999). Principles of Plant Breeding. 2nd edn. John Wiley and Sons, London.

Badiger PK, Rudranaik V, Parameshwarappa KG and Patil MS (2009). Genotype x environmental interactions and 
stability analysis of non-spiny breeding lines in safflower. Karnataka J. Agric. Sci. 22: 978-981.

Breese EL (1969). The measurement and significance of genotype-environment interactions in grasses. Heredity 24: 27-44.

Caligari PDS (1993). G x E Studies in Perennial Three Crops: Old, Familiar Friend or Awkward, Unwanted Nuisance? Proceedings of the 1991 International Society of Oil Palm Breeders Workshop Genotype-Environment Interaction Studies in Perennial Tree Crops. Palm Oil Research Institute of Malaysia, Kuala Lumpur, 1-11.

Comstock RE and Moll RH (1963). Genotype-Environment Interactions. In: Statistical Genetics and Plant Breeding (Hanson WD and Robinson HR, eds.). National Academic Science Natural Environment Research Council, Washington, 164-196.

Eberhart SA and Russell WA (1966). Stability parameters for comparing varieties. Crop Sci. 6: 36-40.

Finlay KW and Wilkinson GN (1963). The analysis of adaptation in a plant breeding programme. Aust. J. Agric. Res. 14: 742-754.

Fisher RA and Mackenzie WA (1923). The manurial response of different potato varieties. J. Agric. Sci. 13: 311-320.

Francis TR and Kannenberg LW (1978). Yield stability studied in short-season maize. I. A descriptive method for grouping genotypes. Can. J. Plant Sci.1029-1034.

Freeman GH (1973). Statistical methods for the analysis of genotype-environment interaction. Heredity 31: 339-354.

Hartley CWS (1988). The Oil Palm. Longmans, London.

Hill J (1975). Genotype-environment interactions - a challenge for plant breeding. J. Agric. Sci. 85: 477-493.

Huhn M (1979). Beitrage zur erfassung der phanotypischen stabilitat. I. Vorschlag einiger auf ranginformationen beruhenden stabilitas parameter. EDP Med. Biol. 10: 112-117.

Hutomo T and Pamin K (1992). Hasil pendahuluan uji keturunan kelapa sawit hibrida D x P dan Dy x P di Sumatera Utara. 2. Interaksi genotipe dan lingkungan terhadap produksi TBS dan komponennya. Bull. Perkeb. 23: 143-154.

Immer FR, Hayes HK and Powers LR (1933). Statistical determination of barley varietal adaptation. J. Am. Soc. Agron. 26: 403-419.

Junaidah J, Rafii MY, Chin CW and Saleh G (2011). Performance of tenera oil palm population derived from crosses between Deli dura and pisifera from different sources on inland soils. J. Oil Palm Res. 23: 1210-1221.

Kang MS (1988). A rank-sum method for selecting high yielding stable corn genotypes. Cereal Res. Commun. 16: 113-115.

Kang MS (1993). Issue in Genotype-by-Environment Interaction. Proceedings of the 1991 International Society of Oil Palm Breeders Workshop Genotype-Environment Interaction Studies in Perennial Tree Crops. Palm Oil Research Institute of Malaysia, Kuala Lumpur, 67-73.

Kang MS and Miller JD (1984). Genotype x environment interactions for cane and sugar yield and their implications in sugarcane breeding. Crop Sci. 24: 435-440.

Kang MS and Pham HN (1991). Simultaneous selection for high yielding and stable crop genotypes. Agron. J. 83: 161-165.

Kang MS, Boquet DJ, Hall W, Hallmark W, et al. (1990). Alternative selection methods that consider stability of performance in corn yield trials. Am. Soc. Agron. 95.

Kang MS, Gorman DP and Pham HN (1991). Application of a stability statistic to international maize yield trials. Theor. Genet. 81: 162-165.

Knight R (1970). The measurement and interpretation of genotype-environment interactions. Euphytica 19: 225-235.

Lee CH and Donough CR (1993). Genotype-Environment Interaction in Oil Palm Clones. Proceedings of the 1991 International Society of Oil Palm Breeders Workshop Genotype-Environment Interaction Studies in Perennial Tree Crops. Palm Oil Research Institute of Malaysia, Kuala Lumpur, 33-45.

Lin CS and Binns MR (1988). A superiority measure of cultivar performance for cultivar x location data. Can. J. Plant Sci. 68: 193-198.

MPOB (2011). Overview of the Malaysian Oil Palm Industry 2010. Available at [http://econ.mpob.gov.my/economy/]. Accessed October 10, 2011. Malaysian Palm Oil Board, Malaysia.

Noh A, Rafii MY, Saleh G and Kushairi A (2010). Genetic performance of 40 Deli dura $\times$ AVROS pisifera full-sib families. J. Oil Palm Res. 22: 781-795.

Perkins JM and Jinks JL (1968). Environmental and genotype-environmental components of variability III. Multiple lines and crosses. Heredity 23: 339-356.

Plaisted RL (1960). A shorter method for evaluating the ability of selections to yield consistently over locations. Am. Potato J. 37: 166-172.

Rajanaidu N, Rao V, Hoong HW, Lee CH, et al (1992). Yield Potential and Genotype x Environment (GE) Studies in Oil Palm (Elaeis Guineensis). Proceedings of the Workshop Yield Potential in the Oil Palm. International Society of Oil Palm Breeders, Kuala Lumpur, 44-57.

Rajanaidu N, Jalani BS, Rao V and Kushairi A (1993). Genotype-Environment Interaction (GE) Studies in Oil Palm (Elaeis Guineensis) Progenies. Proceedings of the 1991 International Society of Oil Palm Breeders Workshop Genotype-Environment Interaction Studies in Perennial Tree Crops. Palm Oil Research Institute of Malaysia, Kuala 
Lumpur, 12-32.

Rao V, Soh AC, Corley RHV and Lee CH (1983). A critical reexamination of the method of bunch quality analysis in oil palm breeding. Palm Oil Research Institute of Malaysia, Kuala Lumpur.

Robbelen G (1990). Mutation Breeding for Quality Improvement - A Case Study for Oilseed Crops. Mutation Breeding Review. Joint FAO/IAEA Division of Nuclear Techniques in Food and Agriculture No. 6: 1-44.

Sabaghnia N, Dehghani H and Sabaghpour SH (2006). Nonparametric methods for interpreting genotype x environment interaction of Lentil genotypes. Crop Sci. 46: 1100-1106.

Shukla GK (1972). Some statistical aspects of partitioning genotype-environmental components of variability. Heredity 29: $237-245$.

Tarmizi AM, Tayeb MD and Zin ZZ (1992). Maximum Yield of Oil Palm in Peninsular Malaysia. Yield Response and Efficiency of Nutrient Recovery. Proceedings of the 1990 International Society of Oil Palm Breeders Workshop Yield Potential in the Oil Palm. International Society of Oil Palm Breeders, Kuala Lumpur, 145-153.

Tiawari DK, Pandey P, Singh RK, Singh SP, et al. (2011). Genotype x Environment Interaction and Stability Analysis in Elite Clones of Sugarcane (Saccharum officinarum L.). Int. J. Plant Breed. Genet. 5: 93-98.

Yates F and Cochran WG (1938). The analysis of groups of experiments. J. Agric. Sci. Camb. 28: 556-580.

Yong YY, Lee CH, Tan ST and Chiu SB (1993). Evaluation of Elaeis Oleifera x Elaeis Guineensis Inter-Specific Hybrids at Five Locations for Genotype x Environment Interaction. Proceedings of the 1991 International Society of Oil Palm Breeders Workshop Genotype-Environments Interaction Studies in Perennial Tree Crops. International Society of Oil Palm Breeders, Kuala Lumpur, 55-62. 